\title{
Formação continuada sobre multiplicação e divisão para professores dos Anos
}

\section{Iniciais e o trabalho coletivo}

\author{
Continuous training on multiplication and division for teachers of the Early Years and collective \\ work
}
Formación continua en multiplicación y división para profesores de Primera Edad y trabajo colectivo

Recebido: 01/09/2021 | Revisado: 13/09/2021 | Aceito: 14/09/2021 | Publicado: 15/09/2021

Yolanda Pinto dos Santos
ORCID: https://orcid.org/0000-0001-5186-7905
Prefeitura Municipal de Vila Velha, Brasil
E-mail: yolandapsc@gmail.com
Sandra Aparecida Fraga da Silva
ORCID: https://orcid.org/0000-0002-0902-627X
E-mail: sandrafraga7@ @mail.com
Dilza Côco
Instituto Federal de Educação Ciência e Tecnologia do Espírito Santo, Brasil
ORCID: https://orcid.org/0000-0001-8371-8517
Instituto Federal de Educação Ciência e Tecnologia do Espírito Santo, Brasil
E-mail: dilzacoco@gmail.com

\section{Resumo}

Este trabalho desenvolve discussões sobre formação continuada de professores dos anos iniciais que ensinam matemática, mais especificamente sobre o conceito de multiplicação e divisão. Apresenta dados de pesquisa de mestrado, produzidos em ação de formação realizada no ano de 2017, com 17 professores da rede pública de ensino (municipal e estadual). Em termos teórico metodológico, a investigação vincula-se aos pressupostos da Teoria Histórico-Cultural e aos princípios do materialismo histórico dialético. A partir desses referenciais, busca-se compreender o fenômeno da formação como movimento de transformação, onde a apropriação de conhecimentos, em uma perspectiva coletiva, contribui para uma nova qualidade das ações docentes, na área do ensino de matemática. A análise dos dados indica que as ações de formação realizadas coletivamente mobilizaram o interesse dos participantes e favoreceu a ressignificação dos conceitos de multiplicação e divisão.

Palavras-chave: Educação Matemática; Formação de professores; Multiplicação e divisão.

\begin{abstract}
This work develops discussions on the continuing education of teachers in the early years who teach mathematics, more specifically on the concept of multiplication and division. It presents master's research data, produced in a training action carried out in 2017, with 17 public school teachers (municipal and state). In theoretical and methodological terms, the investigation is linked to the assumptions of Historical-Cultural Theory and the principles of dialectical historical materialism. Based on these references, we seek to understand the phenomenon of training as a movement of transformation, where the appropriation of knowledge, in a collective perspective, contributes to a new quality of teaching actions in the area of teaching mathematics. Data analysis indicates that the training actions carried out collectively mobilized the interest of the participants and favored the redefinition of the concepts of multiplication and division.
\end{abstract}

Keywords: Mathematics Education; Teacher training; Multiplication and division.

\section{Resumen}

Este trabajo desarrolla discusiones sobre la formación continua de los docentes en los primeros años que enseñan matemáticas, más específicamente sobre el concepto de multiplicación y división. Presenta datos de investigación de maestría, producidos en una acción formativa realizada en 2017, con 17 docentes de escuelas públicas (municipales y estatales). En términos teóricos y metodológicos, la investigación está vinculada a los supuestos de la Teoría Histórico-Cultural y los principios del materialismo histórico dialéctico. A partir de estas referencias, buscamos entender el fenómeno de la formación como un movimiento de transformación, donde la apropiación del conocimiento, en una perspectiva colectiva, contribuye a una nueva calidad de las acciones docentes en el área de la enseñanza de las matemáticas. El análisis de datos indica que las acciones formativas realizadas colectivamente movilizaron el interés de los participantes y favorecieron la resignificación de los conceptos de multiplicación y división.

Palabras clave: Educación Matemática; Formación de profesores; Multiplicación y división. 


\section{Introdução}

A formação continuada pode ser compreendida como um momento de reelaboração, apropriação e reflexão sobre o trabalho docente. Durante os dias letivos, cada aula apresenta sua especificidade, cada turma retorna à proposta da aula de uma maneira. Assim, naturalmente, o professor se vê imerso em um entrelaçado de acontecimentos e, por vezes, necessita sistematizar sua prática, registrar suas aplicações do planejamento e encontrar possíveis pontos de reformulações de sua ação.

Moura (2005) defende uma formação de professores compartilhada desde a formação inicial, para que os alunos das licenciaturas de Pedagogia e Matemática dialoguem sobre seus objetos de estudo e transitem em diferentes áreas.

[...] o que os dados revelam é que a formação do professor, na universidade, requer a realização de ações compartilhadas entre todos aqueles que interagem com os alunos com o objetivo de lhes ensinar conteúdos, sejam eles de matemática, dos fundamentos da educação, ou metodológicos. Fica evidente, também, que a formação inicial deve contribuir para o desenvolvimento de potencialidades nos alunos que lhes permitam considerar a formação contínua como sendo uma característica de sua profissão (Moura, 2005, p. 96).

A proposta, então, é destacar a importância da formação continuada a ser compartilhada e promovida, de forma a integrar diferentes sujeitos que envolvam professores de diferentes escolas/regiões e de diferentes disciplinas, objetivando um estudo sobre o seu trabalho profissional. A troca de experiências com o outro permite a identificação de dificuldades e uma ressignificação de seus conhecimentos e práticas. É importante a compreensão de que, no “ser professor", é imprescindível envolver-se em formação que potencialize a qualidade de seu trabalho.

O autor ainda faz uma reflexão de que as formações (inicial e continuada) precisam deixar latente em seus participantes que o conteúdo não é o objeto central de estudo do professor em formação. É essencial e insubstituível que o professor tenha compreensão da sua atividade principal, que é a Atividade de ensino, que envolve, dentre outras coisas, o conhecimento científico. Todavia, "faz-se necessária a compreensão da complexa trama que envolve a educação escolar e o indispensável compartilhamento de diferentes fontes de conhecimento e espaços de aprendizagem na formação do professor" (Moura, 2005, p. 95).

O docente, então, não é aquele que ensina o saber acadêmico, e sim um educador que apresenta um elo entre o conhecimento e o humano/cidadania. Os professores dos anos iniciais do ensino fundamental necessitam desenvolver o potencial de seus alunos por meio de práticas reflexivas, para além do conteúdo programático. Moura (2005) aponta que um caminho viável para a ascensão de ideais que problematizam/ampliam o objeto de estudo do professor é a formação em parceria, o momento em que os docentes fazem trocas de experiências com seus pares de profissão (ou sujeitos envolvidos no processo), estudam conteúdos coletivamente e possibilidades de abordagens.

O professor não nasce professor. Ele se constitui historicamente; aprende sem se desvincular do mundo que o rodeia; aprende com o outro e aprende também refletindo. O saber e o fazer constituem-se em elos inseparáveis. Formar-se professor é mais do que somente frequentar um curso superior (Lopes, 2009, p. 55).

E, nessa relação dialógica, naturalmente, é desenvolvida uma reelaboração de práticas e metodologias por parte dos envolvidos. A formação docente na perspectiva histórico-cultural destacada por Moretti e Moura (2010, p. 355) consiste sempre em ter "o outro como elemento integrante do ato de formar-se". Nesse sentido, a formação continuada de professores deve, preliminarmente, considerar o docente como sujeito ativo no processo de produção de saberes pedagógicos e deve permitir que cada professor desenvolva novas significações sobre sua prática, tecendo sua reorganização educacional no coletivo, e focalizando suas ações em sua sala de aula.

Moretti e Moura (2010) destacam o papel da "atividade colaborativa" na formação inicial e continuada. Esse tipo de proposta permite que o professor-participante observe que a formação em serviço não pertence ao responsável pela 
organização do encontro e que todos os envolvidos vão, de alguma forma, impactar a produção final daquele momento (Moretti \& Moura, 2010). Ainda de acordo com a perspectiva histórico-cultural, o encontro entre professor-formador e o professor-em-formação deve privilegiar a escuta atenta, a vontade de conhecer o outro, a importância dada aos saberes do grupo e a interação na interlocução do processo, permitindo que os sujeitos envolvidos tenham proximidades em seus objetivos pertinentes aos seus trabalhos como docentes.

Desenvolvemos discussões sobre formação continuada de professores dos anos iniciais que ensinam matemática, mais especificamente sobre conceitos de multiplicação e divisão, que são foco principal de aulas de matemática em turmas do ensino fundamental. Professores dedicam grande parte do tempo de suas aulas em desenvolver em seus alunos conhecimentos acerca das operações de multiplicação e divisão, mas alguns possuem dificuldades com o ensino de tais conceitos. Sendo assim, existe uma demanda de professores que são motivados a entrarem no movimento de formação continuada para ampliar seus conhecimentos, superar inseguranças e aprender novas abordagens da multiplicação e divisão. Conhecendo essa realidade, em 2017, ofertamos uma formação continuada em formato de curso de extensão.

Este artigo apresenta dados de pesquisa de mestrado, produzidos em ação de formação continuada de professores da rede pública de ensino que são regentes de turmas de $1^{\circ}$ ao $5^{\circ}$ ano. Foi realizado um curso de extensão no Instituto Federal com 10 encontros presenciais e com tarefas pelo ambiente virtual (Moodle) com o objetivo de analisar o movimento formativo e mudanças evidenciadas pelos professores participantes relacionadas à compreensão dos conceitos de multiplicação e divisão e de possíveis propostas de ensino nos anos iniciais. Com isso, realizamos um recorte para este artigo com o objetivo de analisar o movimento de mudança de qualidade na atividade de ensino de professores que ensinam Matemática nos anos iniciais do ensino fundamental em um ambiente de formação continuada, sobretudo, como viam, trocaram conhecimentos e modificaram o olhar sobre o conhecimento teórico matemático das operações de multiplicação e divisão, discutido no curso e aplicado em suas salas de aula.

Ensinar e aprender matemática vêm sendo considerado um desafio tanto para professores como para alunos. Embora pesquisas e discussões nessa perspectiva tenham se ampliado, parece-nos fazer parte do senso comum o fato de que o fracasso escolar de muitos estudantes está atrelado a essa área do conhecimento. Uma das justificativas seria o ensino por meio de aulas ainda, em sua maioria, ditas tradicionais, através de repetições, cópias e memorizações de regras e algoritmos (Zuge e Lopes, 2016, p. 160).

Durante a pesquisa do mestrado (Santos, 2019), a disciplina de matemática era tida como a mais incompreendida e complicada pelos sujeitos da pesquisa, o que ocasionou em 542 inscrições para o curso de extensão em "Multiplicação e divisião nos anos iniciais". Com isso, professores que desejam potencializar seu trabalho, buscam cursos, capacitações e pósgraduações que ofereçam oportunidades de momentos de estudo teórico-prático.

O trabalho faz uma contextualização teórica dos conceitos que são utilizados como base da pesquisa e que norteiam a análise de dados realizada, no campo educacional e psicológico. Após evidenciamos o percurso metodológico adotado para o desenvolvimento deste artigo e a análise dos dados encontrados. Na análise encontramos indícios suficientes para um debate teórico em que encontramos, em diferentes meios, possibilidades de aprendizagens. Com isso, por meio das considerações finais apresentamos as conclusões que foram possíveis com o findar da pesquisa.

\section{Referencial Teórico}

O psicólogo russo Lev. S. Vigotski (1896-1934) fomentou uma nova perspectiva de pensar o processo de aprendizagem afirmando que o sujeito potencializa seu desenvolvimento mental por meio dos seus aspectos sócio-históricoculturais na qualidade de educando. Relacionando o trabalho do pedagógico à psicologia, Vigotski (2010, p. 461) afirma que “a educação é um processo de mútua e contínua adaptação de ambos os campos, no qual a parte mais dinâmica e 
terminantemente ativa é ora o orientador, ora os orientados". Assim, o que está em análise não é o conhecimento gerado nem o resultado, e sim todo o processo de desenvolvimento e, por conseguinte, de aprendizagem. O professor, de acordo com essa teoria, tem a função de promover, usando diferentes estratégias, situações potencializadoras de descobertas e reflexões que permitam que o sujeito se desenvolva.

Embora seja do início do século passado, a teoria vigotskiana ainda é capaz de apontar alguns problemas relativos ao ensino, principalmente no caso de o professor assumir o papel de organizador intencional de situações para o trabalho com os conteúdos. Hoje, perante a globalização e a informatização, encontramos, no processo de ensino e aprendizagem, diversos mecanismos de acesso à informação no qual o professor assume o papel de organizar o ensino para que os alunos tenham acesso aos conteúdos organizados pela humanidade como necessários para as novas gerações. Por isso, utilizamos a perspectiva histórico-cultural para superar esses percalços. O formador atuante na perspectiva histórico-cultural não dissocia a vida cotidiana dos sujeitos do processo de ensino; ao invés disso, utiliza-se da produção social, histórica e cultural do próprio formando e do trabalho já desenvolvido pela sua sociedade como ponto de partida e de chegada para a apropriação do conhecimento. Vigotski (2010), visando a um novo olhar sobre o profissional da educação que gerencia o ensino, leva em conta que:

[...] o pedagogo será um ativo participante da vida. Seja no campo da ciência teórica, do trabalho ou da atividade prático-social, através do objeto que ensina ele estará ligando a escola à vida. Assim, o trabalho pedagógico estará necessariamente fundido ao amplo trabalho social do cientista ou do político, do economista ou do artista (Vigotski, 2010, p. 456).

Um dos problemas da educação é realizar um planejamento de ensino que não contemple a participação e a subjetividade do aluno a que se dirige; então, uma educação que seja integral precisa estar vinculada ao mundo fora de seus muros. Se o discente, ao desenvolver o trabalho educativo, perceber a sua importância como criador de trabalho, multiplicador de ideias e questionador dos conceitos já existentes, contribuirá para realizar o papel da escola como local propício para apropriação dos conhecimentos organizados pela humanidade.

Moura (2000, p. 70-71) faz uma analogia para entender o movimento da ação educativa, entre a atividade de ensino e as cenas de um filme. Inicialmente, o autor enfatiza o contínuo movimento desses processos, impossibilitando, assim, a análise de forma isolada, focando a leitura de cenas que ocorrem na comunidade educativa e a elaboração dessas relações constituindo a coletividade.

A complexidade da atividade de ensino exige a observação de múltiplos fenômenos para que possa ser compreendida. Vamos nos valer de algumas comparações em busca da compreensão desta complexidade, de modo que possamos apreender também como a coletividade de aprendizagem poderá coordenar as ações de seus membros, com o objetivo de inserir todos no movimento de criação da solução do problema que o coletivo deverá resolver: dar significado às ações coletivas (Moura, 2000, p. 69).

Percebemos, então, que, nessa perspectiva, a leitura das cenas que ocorrem no movimento de formação será objetivada em identificar a configuração de um coletivo, ou seja, perceber que, durante o processo, foi constituído saberes por meio do grupo de envolvidos na cena. Mas, para a constituição desse coletivo, sabemos da existência de necessidades individuais, o qual, compartilhado e reconhecido como legítimo pelo grupo, ocasiona a identificação uns com os outros de um coletivo com necessidades, motivos e objetivos que convergem em alcançar uma mudança de qualidade de sua Atividade de ensino. "Para ser coletividade é preciso ser um organismo social e, portanto, ter órgãos de direção e coordenação, autorizados para representarem, ante todos, os interesses da coletividade em particular, e da sociedade” (Makarenko, 1977 apud Moura, 2000).

Por meio dessas definições, Moura (2000) aponta ações que promoverão a concretização de um coletivo, atendendo ao real conceito desse termo diante da teoria histórico-cultural e ressaltando que o fato de colocar o sujeito para desenvolver 
uma tarefa em grupo não constitui coletividade. Assim, a primeira ação coletiva do grupo é encontrar os objetivos em comum dos participantes, ou seja, universalizar as necessidades pelas quais os fazem constituir-se como um coletivo e promover a coletividade. Alcançando isso, os sujeitos reconhecerão que, juntos, podem alcançar a melhoria de suas ações didáticas por meio das conquistas do grupo. A ação seguinte seria a sistematização do projeto que satisfaz as necessidades do grupo, a fim de alcançar a coletividade. Nesse processo de construção, percebemos que o grupo se constitui já como coletivo, no movimento de coletividade. Não temos como constatar, de forma materializada, a constituição da coletividade, mas buscamos evidências por meio dos compartilhamentos e das ações dos sujeitos, que são os indícios do potencial movimento coletivo. Nesse movimento, é interessante entendermos a Matemática como criação humana, ou seja, parte de uma cultura que se constituiu na história por alguma necessidade do homem e sobrevive por meio das relações sociais.

[...] a ideia de número natural não é um produto puro do pensamento, independe da experiência; os homens não adquiriram primeiro os números para depois contarem; pelo contrário, os números naturais foram se formando lentamente pela prática diária de contagens (Caraça, 2003, p. 4).

Ou seja, a civilização humana iniciou o processo de contagem nas suas tarefas essenciais, o qual fomentou agrupamentos e, assim, a criação dos números naturais e o sistema de numeração.

No coletivo de professores, num contexto de sala de aula, entender a Matemática como parte de nossa cultura, além de situá-la historicamente, pode contribuir para o processo de ensino e aprendizagem em Matemática, proporcionando aos alunos o acesso a algumas culturas e possibilitando o resgate da própria identidade cultural. Dentro das aprendizagens da disciplina Matemática nos anos iniciais, o que fica mais evidenciado nas turmas dos anos iniciais são as quatro operações (adição, subtração, multiplicação e divisão). A esses conhecimentos o professor dedica grande período do seu planejamento e de suas aulas, tentando proporcionar ao aluno a sistematização dos procedimentos que compreendem a resolução de cada operação, que, muitas vezes, ocorre de forma fragmentada, desconsiderando a relação indissociável entre essas operações. Dentro dessa temática, as operações de multiplicação e divisão são as que mais geram insegurança em docentes e, consequentemente, em discentes, por apresentar maior estímulo à interpretação, abstração e procedimento.

\section{Metodologia}

A Matemática é uma ciência e resultado de um processo histórico de produção de conhecimento, no entanto, permeado pelo contexto atual, pode reproduzir a luta de classes e, consequentemente, a exclusão social.

O conhecimento escolar deve ser organizado como uma síntese desses avanços e conquistas, com o propósito de produzir nos alunos o aumento das possibilidades de posicionamento livre e consciente diante das alternativas de futuro existentes na prática social (Duarte, 2016, p. 99).

Na nossa proposta, os sujeitos integraram um processo de formação continuada de caráter liberativo que promoveu a produção de conhecimento consciente e orientado. Nosso intuito era proporcionar a liberdade de participação, de exposição de ideias, de contraponto, de negação e de reflexão, imersos em um ambiente colaborativo que priorizasse o diálogo entre os sujeitos e com o conhecimento científico. Salientamos primordialmente a importância do saber científico dentro da escola e, por consequência, compartilhado com o professor.

[...] o comportamento humano se forma a partir das peculiaridades e condições biológicas e sociais de seu desenvolvimento. $\mathrm{O}$ fator biológico determina a base, o fundamento, das reações herdadas, de cujos limites o organismo não pode sair e sobre as quais se constrói o sistema de reações aprendidas. Ao mesmo tempo, é evidente que esse novo sistema de reações é totalmente determinado pela estrutura do ambiente no qual o organismo cresce e se desenvolve. Por esse motivo, toda educação tem inevitavelmente um caráter social (Vigotski, 2003, p. 75). 
Nesta perspectiva o professor não pode dissociar o seu trabalho de ensino do conhecimento produzido ao longo da história e da cultura em que aquele aluno está inserido. Devemos utilizar a produção social, histórica e cultural do próprio formando e do trabalho já desenvolvido pela sociedade como ponto de partida e de chegada para a apropriação do conhecimento. Exemplificando, Moura (2000, p. 70-71) faz uma analogia para entender o movimento da ação educativa, entre a atividade de ensino e as cenas de um filme. Inicialmente o autor enfatiza o contínuo movimento desses processos, impossibilitando, assim, a análise de forma isolada, focando a leitura das cenas que ocorrem na comunidade educativa e a elaboração dessas relações constituindo a coletividade.

Para fins metodológicos, entendemos que nossa pesquisa é qualitativa e se aproxima do método de materialismo histórico-dialético que privilegia a análise do processo de transformação, possibilitando, assim, compreender o movimento da formação dos participantes mediante a proposta desenvolvida nesta pesquisa. Este método está inserido na perspectiva teórica deste trabalho, teoria histórico-cultural, principalmente nas pesquisas em educação.

O conceito de 'atividade' tem como base epistemológica o Materialismo Histórico e Dialético de Karl Marx, cuja categoria fundante é trabalho [...]. Vigotski se apropria do conceito de atividade por entendê-lo como elemento essencial na formação e desenvolvimento da consciência. Por sua vez, Leontiev com o propósito de aprofundar os estudos de Vigotski em decorrência da morte precoce desse teórico, ancorado em suas ideias, elabora a Teoria da Atividade, dando destaque à tríade atividade-consciência-personalidade e, assim, avança significativamente no que tange à problemática do desenvolvimento do psiquismo (Araujo, 2016, p. 112).

Para Leontiev (1978) o homem precisa entrar em atividade para construir significado e sentido para aquele conhecimento. Por meio das mediações, o ideal é que o motivo e o objeto da atividade sejam os mesmos, dando significação pessoal a atividade. Deste modo, o professor tem o trabalho de ensino focalizado em desenvolver meios para que o aluno se aproprie dos objetos e conhecimentos que foram produzidos historicamente, colocando o aluno em atividade, considerando o seu conhecimento prévio do aluno.

Na proposta desta pesquisa, um dos pontos essenciais foi o experimento didático dita como uma a intervenção ativa do pesquisador nos processos psíquicos (Cedro, 2008, p. 105), afastando-se da ideia em que o professor sujeito da pesquisa será observado pelo pesquisador e avaliado quanto às suas aprendizagens e indo contra o papel individualizado encontrado em algumas propostas de formação continuada. Na sua tese de doutorado, Cedro (2008) discrimina as características do experimento didático.

[...] pelo caráter qualitativo dos dados coletados; pela orientação para os processos descobertos pelos indivíduos ao se apropriarem dos conhecimentos inerentes à formação do professor; pela participação ativa do pesquisador na aprendizagem dos indivíduos; pela constante interação entre as observações coletadas e o planejamento futuro das ações; pela natureza longitudinal do trabalho desenvolvido (Cedro, 2008, p. 106).

Os facilitadores do curso foram os próprios pesquisadores, o que dá mais identidade ao que é realizado, faz maior aproximação entre os pressupostos teóricos fundamentados e as práticas realizadas na formação e promove um acompanhamento cronológico das aprendizagens realizadas nos percursos dos processos formativos.

Cedro \& Nascimento (2017), fundamentados em Vigotski, evidenciam que a formulação desse método de estudo tem uma forte relação com o objeto da pesquisa, o desenvolvimento das funções psíquicas superiores no seu processo de humanização.

Vigotski parte, assim, de uma necessidade metodológica fundamental: elaborar um novo método para a Psicologia que conseguisse captar e explicitar a natureza histórico-social do psiquismo humano. Isso quer dizer que os métodos até então existentes [...] não se constituíam ao mesmo tempo como um método histórico do psiquismo humano (Cedro \& Nascimento, 2017, p. 32). 
Assim, segundo eles, analisar historicamente remete ao estudo da transformação tanto do objeto pesquisado quanto das suas propriedades e relações, capturando o fenômeno no que ele era, é e no que pode vir a ser. Segundo Lopes \& Silva (2020, p.22) "O conteúdo e o desenvolvimento da formação continuada têm que fazer parte da necessidade do professor", ou seja, o docente desenvolverá melhor quando possui motivação pessoal/profissional para buscar o movimento formativo.

Ao inserirmos essa metodologia em nossa pesquisa, objetivamos analisar o movimento de mudança de qualidade na atividade de ensino de professores que ensinam Matemática nos anos iniciais do ensino fundamental, sobretudo, como viam, trocaram conhecimentos e o seu novo olhar sobre o conhecimento teórico matemático em multiplicação e divisão, discutido no curso e aplicado em suas salas de aula. O objetivo, então, é investigar a base psicológica no processo de ensino, as relações e interações entre todos os sujeitos envolvidos e suas trocas que potencializaram o desenvolvimento psíquico cujo foco são os objetivos teóricos. A intervenção dos pesquisadores assume um papel central, visto que eles promovem uma interação de caráter de planejamento e participação permanentes com os sujeitos da pesquisa, tentando maximizar suas aprendizagens e motivação pelo novo conceito apropriado, sabendo ter atitudes intencionais no seu processo de mediação (CEDRO; MOURA, 2016).

Martins e Eidt (2010) conduzem o professor ao seu trabalho de ensinar, sendo essa a sua atividade principal. Esse termo decorrente da teoria da atividade assim afirma:

A atividade principal é aquela cujo desenvolvimento governa as mudanças mais importantes nos processos psíquicos e traços psicológicos da personalidade da criança em cada estágio de seu desenvolvimento: devemos, por isso, falar da dependência do desenvolvimento psíquico em relação à atividade principal e não à atividade em geral (Martins \& Eidt, 2010, p. 678).

O professor em atividade estabelece relação entre a realidade e os seus conhecimentos com as propostas evidenciadas. Essa relação não pode ser passiva, e sim um processo de interação entre o real e o novo, entre o externo e o interno e entre o individual e o coletivo.

Os sujeitos da pesquisa foram professoras dos anos iniciais que ensinam Matemática, todas da rede pública de ensino (municipal ou estadual), que eram regentes de sala de aula em 2017. Foi ofertado, em colaboração com o IFES, um curso de extensão mediante um edital para inscrições com limite de 20 vagas para participantes do curso de extensão no estudo de multiplicação e divisão. O curso contou com 10 encontros presenciais e também com carga horária na plataforma MOODLE (ensino remoto).

\section{Resultados e Discussão}

Já no primeiro encontro, as professoras participantes (todas eram do sexo feminino) tiveram uma iniciação aos conceitos que seriam trabalhados ao longo dos encontros. Foram apresentadas as ideias contidas na multiplicação e divisão, em uma lista com situações-problema que envolviam as ideias dessas duas operações básicas. Ao fim, abriu-se o momento para trocarmos ideias sobre o papel do professor ante a diversidade de caminhos e estratégias adotadas pelos alunos nas aulas de Matemática e a maneira como o professor reage a esse universo de pensamentos matemáticos dentro da mesma situaçãoproblema. Diferentemente do que presenciamos, às vezes, na educação escolar, na qual somente uma forma de resposta está correta, a conclusão do grupo formalizou que há diferentes maneiras de chegar ao que é proposto na situação-problema, dando conta de satisfazê-la. O que percebemos é que, inicialmente, elas pegaram suas listas individualmente e começaram a resolver as situações-problema, posteriormente, foram estimuladas a partir para o coletivo. 
Com o compartilhamento, percebemos que elas apagavam suas respostas e começavam, em duplas ou trios, a dialogar sobre possíveis caminhos em que, por vezes, deixaram de ser somente o algoritmo e passaram a ser outras formas de representar o pensamento matemático. Ocorreu também que algumas participantes tiveram uma interpretação diferente da outra na leitura da situação-problema, abrindo para o diálogo, e, assim, elas chegavam a um acordo, como na questão número um da lista de exercícios, que pedia as possíveis combinações de sabores de pizza e o recheio da borda.

Figura 1: Cursista resolvendo situação-problema no quadro

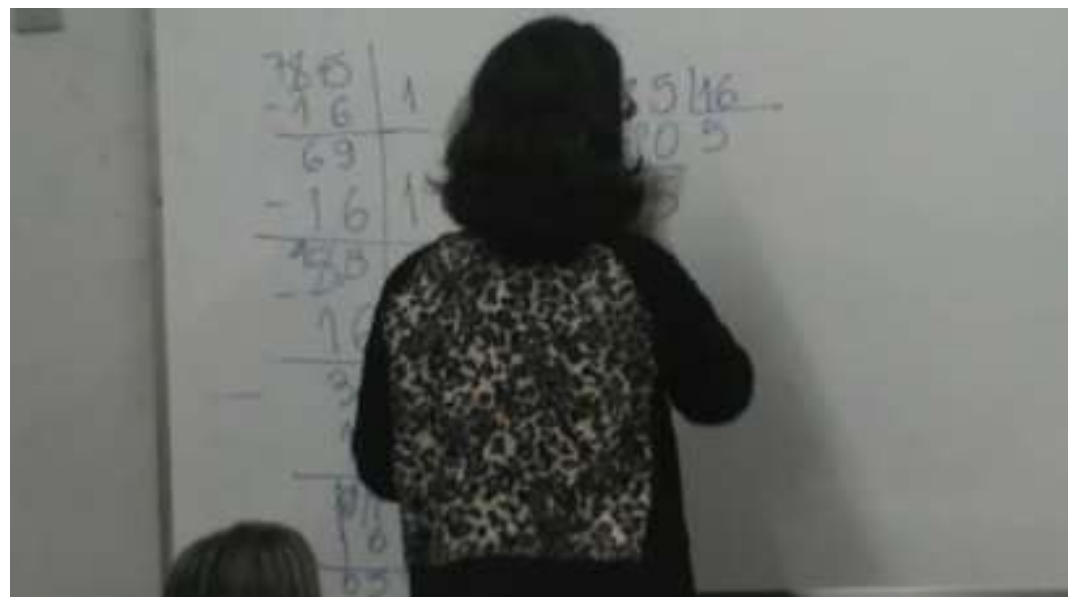

Fonte: Santos (2019, p. 169).

Iniciamos também, nesse primeiro encontro, a problematização de considerar a multiplicação, a divisão e seu ensino, restrito somente ao algoritmo e seus procedimentos. Antes de compreenderem os procedimentos de cálculo de multiplicação e divisão, os alunos precisam entender a estrutura do conceito envolvido e passar por diferentes estratégias de resolução, para que, quando depararem a ideia de multiplicação e divisão em uma nova situação-problema, apliquem sua experiência com essa ideia, para ajudá-los a pensar essa nova tarefa.

[...] formar nas crianças representações materialistas firmes para produzir nelas o pensamento independente e melhorar significativamente a formação artística e estética; elevar o nível ideológico e teórico do processo de ensino e educação, expor com precisão os principais conceitos e as ideias básicas das disciplinas escolares; erradicar quaisquer manifestações de formalismo no conteúdo e métodos de ensino e no trabalho de formação, e aplicar amplamente as formas e métodos ativos de ensino, etc (Davídov, 1988 apud Rosa; Damazio \& Alves, 2013, p.62).

De acordo com nossos pressupostos teóricos, o foco central do trabalho do professor é promover um ambiente escolar que gere o desenvolvimento do pensamento teórico, valorizando o ambiente escolar como propiciador de acesso aos conceitos científicos produzidos historicamente pela humanidade e formando generalizações que devem ser passadas às novas gerações. Diferentemente dos modelos de ensino da Matemática que vemos tradicionalmente, com o objetivo primordial no procedimento simplificado e na resposta direta, no qual o estudante encontra a resposta sem dar significado a ela, a proposta davydoviana requer do processo de ensino e aprendizagem um aprofundamento científico e contextualizado, passando a incluir o aluno ao percurso histórico dos conceitos de multiplicação e divisão e suas necessidades e aplicações.

No oitavo encontro, iniciamos a dinâmica de apresentação dos relatos de experiências. A proposta era que cada cursista desenvolvesse, em sala de aula, uma prática envolvendo multiplicação e/ou divisão, segundo as colaborações trazidas pelo curso, e elaborasse um relato de experiência sistematizando como foram essa dinâmica com seus alunos, os resultados obtidos, a participação dos alunos, os pontos positivos e negativos e os conceitos matemáticos que foram trabalhados. Além de terem que postar na plataforma Moodle o relato de experiência, nos três últimos encontros do curso, cada uma delas teve 
espaço para apresentar o seu trabalho, por meio de fotos, vídeos, atividades escritas, material utilizado e recursos multimídias (Datashow, notebook...).

No relato de experiência apresentado a seguir, observamos uma das participantes expondo a influência da formação continuada na sua forma de avaliar e utilizar o livro didático.

Quadro 1: Apresentação de relato de experiência da Milena.

MILENA: Eu peguei a proposta da gente trabalhar o livro, nós fizemos aqui a avaliação do livro didático, é uma ótima forma de experimentar o material didático que eles têm. Como as concepções do livro podem ajudar ou não.

[Projeção do Datashow de uma página do livro que a escola dela utiliza.]

MILENA: Esse livro é do segundo ano e já aborda uma questão que nós falamos muito, ele cobra o algoritmo já no segundo ano. Sempre ele pede para escrever em forma de operação à resposta das questões.

[Leitura da tarefa do livro de divisão de peixes no aquário.]

MILENA: As ideias desse livro em relação à abordagem, ilustração e os questionamentos, eu acho que está bem voltado ao que a gente conversou no curso. Só achei que já fazer a cobrança do algoritmo eu já não sei. Quando realizamos essa atividade, eu não cobrei essa parte dos alunos, pedi para que representassem como conseguisse. Alguns representaram com adição, outros com subtração, alguns conseguiram representar a ideia da divisão, e outros fizeram multiplicação. Como nós vimos aqui, existem vários caminhos, uns mais longos e outros mais curtos, não tem certo ou errado. Fui deixando eles fazerem sem cobrar essa parte do algoritmo.

[Foto dos alunos realizando a tarefa.]

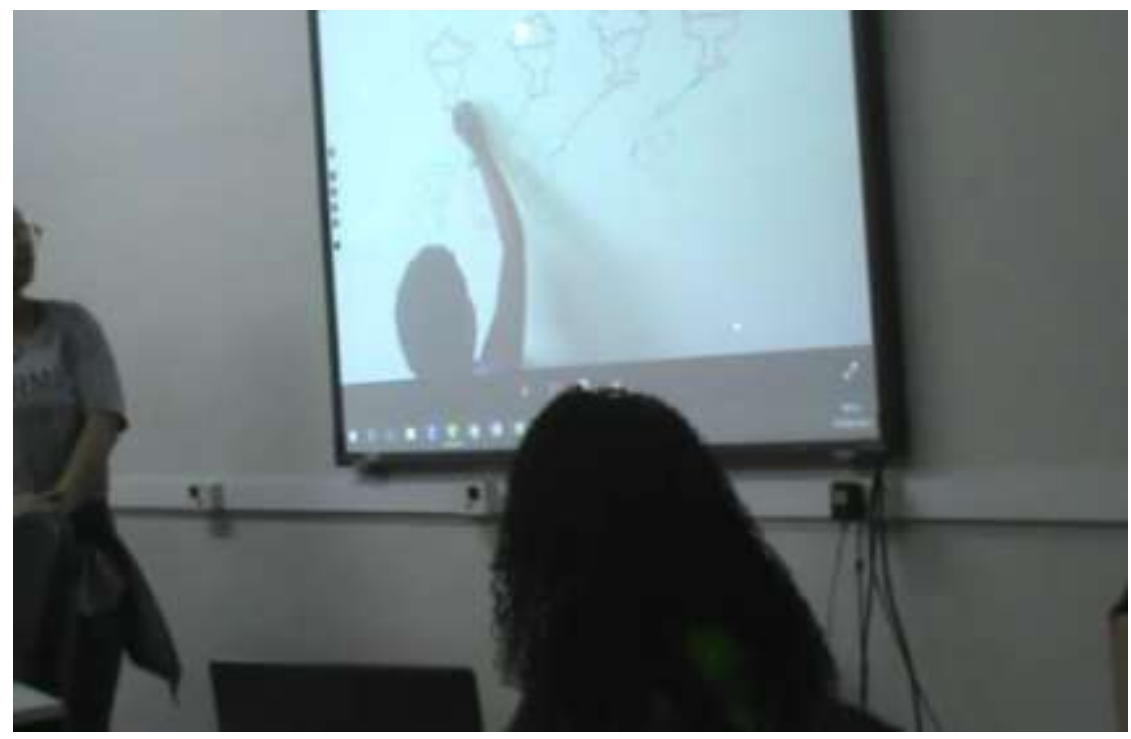

A Milena, depois disso, trouxe uma atividade xerocada que ela desenvolveu com os alunos.

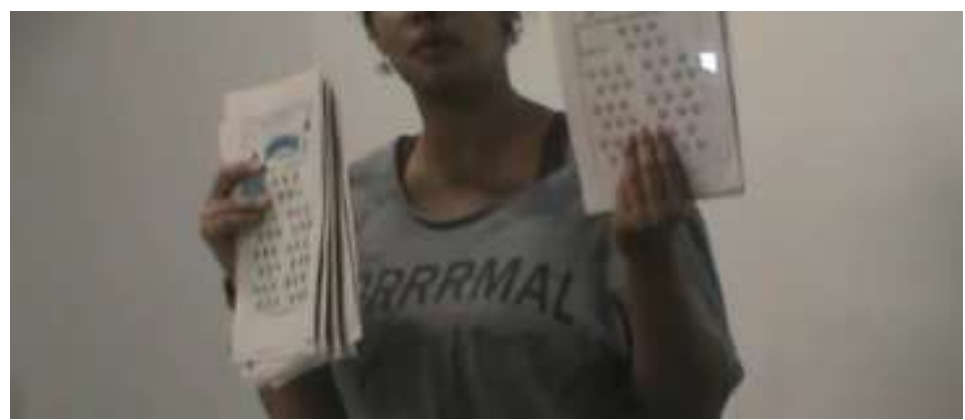


MILENA: Nessa atividade, eu dei para eles moedinhas de papel, e eles tinham que dividir essa quantidade de moedinhas nos 5 saquinhos. Cada saquinho ficando com a mesma quantidade de moedinhas. Depois perguntei quantas moedinhas tinha cada saquinho e quantas moedinhas tinha em todos os saquinhos juntos. Eu achei que nessa atividade eu trabalhei divisão e multiplicação ao mesmo tempo. Eu tive aluno que contou de um a um, eu tive aluno que fez a adição das parcelas e tive alunos que fizeram a multiplicação.

Fonte: Santos (2019, p. 172).

No decorrer e ao final do curso, percebemos que todas as participantes que apresentaram o relato de experiência conseguiram desenvolver atividades realizadas no curso com a sua turma. $\mathrm{O}$ relato anterior demonstra que o modo como a professora conduziu seu processo de ensino foi alterado ante suas novas concepções acerca dos conceitos de multiplicação e divisão, fazendo-se necessária a adaptação às tarefas encontradas no livro didático, não deixando em desuso e, também, não seguindo sistematicamente. Ela traz pontos importantes que destacam indícios de mudança de qualidade em sua atuação, conforme mostramos a seguir.

Para compreender o que a professora destaca sobre a análise do livro didático, pontuamos que, no sexto encontro, trouxemos como proposta realizar a análise de alguns livros didáticos de Matemática dos anos iniciais adotados pelo PNLD (Programa Nacional do Livro Didático) seguindo os critérios indicados no Quadro 2:

Quadro 21: Análise de livro didático.

\begin{tabular}{|c|c|}
\hline Tópicos Analisados & Aspectos Analisados \\
\hline Categorização & $\begin{array}{l}\text { Título; } \\
\text { Autores; } \\
\text { Ano de publicação; } \\
\text { Editora; } \\
\text { Ano; } \\
\text { Número de páginas; } \\
\text { Unidade referente à multiplicação/divisão. }\end{array}$ \\
\hline Multiplicação & $\begin{array}{l}\text { Ideia de "adição de parcelas iguais"; } \\
\text { Ideia de "disposição retangular"; } \\
\text { Ideia de "proporcionalidade"; } \\
\text { Ideia de "combinatória". }\end{array}$ \\
\hline Divisão & $\begin{array}{l}\text { Tipo "partitiva"; } \\
\text { Tipo "quotativa". }\end{array}$ \\
\hline Situações-problemas & $\begin{array}{l}\text { Demonstração da relação entre a multiplicação e a divisão; } \\
\text { Exemplos que vão ao encontro da perspectiva teórica evidenciada. }\end{array}$ \\
\hline
\end{tabular}

Fonte: Santos (2019).

Assim, focamos problematizar como as situações-problema faziam essa relação entre a multiplicação e divisão, se eram tratadas em capítulos diferentes, sem evidenciar que pertencem ao mesmo raciocínio, e se essas situações utilizavam alguma estratégia que desencadeasse o aluno a motivar-se ante a problemática envolvida. 
Todos os livros que analisamos traziam as operações de adição, subtração, multiplicação e divisão em capítulos separados e sempre nessa ordem. Percebemos assim, que a abordagem teórica que fomentamos durante o curso não acompanha o índice dos livros didáticos. O problema consiste em o professor querer seguir o livro como manual e fornecer ao aluno uma aprendizagem procedimental e mnemônica. A utilização do livro didático é muito importante, pois é o material concreto de mais fácil acesso nas escolas públicas, tendo o professor para organizar e planejar de que forma utilizá-lo, no intuito de agregar conhecimentos no trabalho com a área de Matemática.

No sétimo encontro, trouxemos a ideia de utilizar os conceitos de dividir e multiplicar, utilizamos um vídeo que apresentava, por meio de teatro, uma situação em que existiam três pães, para fazer seis sanduíches ${ }^{1}$. Essa estratégia foi escolhida por ser um vídeo, uma das formas de promover uma situação desencadeadora, sendo "um recurso didático que tem por objetivo colocar o sujeito que aprende diante da necessidade do conceito a ser ensinado" (MORETTI, 2007, p. 106). Uma das professoras participantes levou o vídeo para a sua sala de aula e desenvolveu, com as duas turmas a que leciona, essa situação-problema.

Percebemos, por meios das cenas evidenciadas nesses tópicos, o movimento de mudança da ideia de formação continuada a qual as participantes estavam acostumadas antes de participar do curso. Durante os encontros e nos outros meios virtuais de comunicação e estudo, as professoras reconheceram que a dinâmica dos encontros direcionava a construção coletiva das apropriações do grupo, porque o contato com o outro estabelecia o processo de formação e, com o passar dos encontros, elas valorizavam, a todo o momento, a fala das companheiras com quem estabeleciam suas apropriações. Assim, trazemos o foco para o coletivo, sendo este o ponto diferente daquele que ocorre nas demais formações comumente ofertadas. Por meio do grupo e das relações entre as participantes, os novos conhecimentos surgiram e tiveram a chance de serem apropriados à medida que eram trabalhados na participação efetiva dos envolvidos.

\section{Considerações Finais}

Ao longo do curso, ficou nítido que as participantes, à medida que íamos fluindo nos assuntos, sempre tinham algo a exemplificar do que já vivenciaram, ou apresentavam alguma situação ocorrida em sua escola que precisaria ser revista, ou ainda apresentavam seus problemas no ensino de Matemática, ao passo que, em grupo, chegássemos a um acordo coletivo sobre o que pensar a respeito do exposto. No decurso das análises dos dados, percebemos indícios de como a metodologia de ensino delas foi ampliada, o modo como veem a multiplicação e a divisão, o sistema de numeração decimal, quando abriram novas possibilidades de ensino e de aprendizagem dos alunos. Destacamos que dois aspectos, que foram sintetizados em seus eixos de análise, se mostraram relevantes para a aprendizagem das professoras: a possibilidade de apropriação dos conceitos multiplicação e divisão e as colaborações do coletivo.

Favorecendo a pesquisa e análise do nosso trabalho, foi realizada uma formação continuada, definimos ações necessárias para o desenvolvimento desta pesquisa, que chamamos de ações formativas em multiplicação e divisão. Analisamos que conseguimos constituir um espaço de aprendizagem em formação continuada para professores dos anos iniciais do ensino fundamental objetivada num curso de extensão, em que todas as 17 participantes do curso e a equipe organizadora se integravam de forma a se reconhecerem como um grupo único. Ou seja, foi promovido e proporcionado um espaço em que os sujeitos se sentiam à vontade para expor suas ideias, seus contrapontos e discordâncias, ríamos e consolávamos uns aos outros quando necessário. Nesse ambiente, foi muito mais fácil abrir possibilidade de ensino, o que fez os encontros fluírem com naturalidade e motivação.

\footnotetext{
${ }^{1}$ https://www.youtube.com/watch?v=OJ69AD3suvU
} 
Outra ação formativa foi "proporcionar momentos de relatos de experiências para que as professoras, no coletivo, tivessem possibilidades de se apropriassem de conceitos sobre multiplicação e divisão" e "propor discussões sobre situações de ensino que buscassem potencializar o ensino de multiplicação e divisão nos anos iniciais". Inicialmente, as professoras esperavam que nosso formato de formação continuada fosse no formato de um ministrante falando e todos os outros ouvindo $\mathrm{e}$ executando tarefas. Com o passar dos encontros, elas entenderam e faziam a dinâmica de que todos eram importantes e tinham suas falas, experiências, questionamentos e relatos que eram valorizados. Sempre reunidas no coletivo, tínhamos o objetivo de levar o grupo a chegar à mesma generalização, todas se ajudando para superar obstáculos e alcançar novos conhecimentos.

A escola possui autonomia de se desenvolver como espaço libertário, mesmo perante o sistema hegemônico do capital? Para que se alcance essa autonomia, é necessário que o professor, além de saber o seu papel profissional e social, a todo o momento se constitua com seus ideais de resistência e reflexão perante o que lhe é posto. Encontramos, então, um diferencial da profissão de professor: ser agente de luta visando garantir que os alunos tenham suas capacidades desenvolvidas e sejam imergidos na sociedade a que pertencem, superando o modelo capitalista de desenvolvimento desigual dos cidadãos.

$\mathrm{Na}$ contramão do que observamos nas formações de professores, encontramos muitos referenciais que valorizam a profissão de professor, sendo qualificado em coletivo, digo, que o espaço de aprendizagens e novos conhecimentos sejam decididos dentro de um grupo cujos objetivos se unem. Com a teoria histórico-cultural, evidencia-se que o trabalho docente, nas suas ações para além do ensino, objetivando o desenvolvimento conceitual e metodológico de suas práticas, é tecido na relação com o outro. O professor, perante suas necessidades, imerge em um grupo no qual se reconhece como seus pares e, nesse coletivo, fomenta suas problemáticas, a fim de superar e mudar a qualidade do seu trabalho docente. isso ocorreu na formação continuada que desenvolvemos.

Quando estamos em um momento de formação continuada de professores, privilegiamos a organização em coletivo do grupo, para que, no compartilhamento de práticas e conhecimentos, novos conceitos surjam elaborados na mediação dos sujeitos, promovendo novos olhares sobre suas ações como professor (LOPES et al., 2016). Com essa abordagem, é indispensável que os formadores promovam momentos em que os indivíduos sejam colocados em cooperação, tanto para se reconhecerem como grupo e se sentirem à vontade/seguros quanto para se abrirem para alcançar novos níveis cognitivos ante o conhecimento gerado pelo coletivo.

Para conhecer mais sobre esse processo formativo e a pesquisa indico a leitura de Santos (2019), onde é apresentado a pesquisa completa. Sugerimos que esses estudos e práticas tenham continuidade por meio de outras pesquisas na linha de formação de professores que ensinam matemática, sobretudo com foco em novas oportunidades de formação para os docentes. Os sujeitos da pesquisa que novos movimentos formativos seriam esperados, pois estes sentem a necessidade de continuar seus estudos na Educação Matemática.

\section{Referências}

Araujo, N. A. (2016). Indícios de apropriação das significações de conceitos matemáticos por professores em atividade de aprendizagem. In: Lopes, A. R. L. V.; Araujo, E. S.; Marco, F. F. (Org.). Professores e futuros professores em atividade de formação. 1 ed. Campinas: Pontes Editores. 1, 101-130.

Caraça, B. J. (2003). Conceitos Fundamentais da Matemática. Lisboa, Gradiva.

Cedro, W. L. (2008). O motivo e a atividade de aprendizagem do professor de matemática: uma perspectiva histórico-cultural. 2008. 242. Tese (Doutorado em Educação) - Programa de Pós-Graduação da Faculdade de Educação da Universidade de São Paulo, São Paulo.

Cedro, W. L. \& Moura, M. O. (2016). Possibilidades metodológicas na pesquisa em educação matemática: o experimento didático. Educativa. Goiânia. 19(1), 121-38.

Cedro, W. L. \& Nascimento, C. P. (2017) Dos métodos e das metodologias em pesquisas educacionais na teoria histórico-cultural. In: MOURA, Manoel Oriosvaldo de (Org.). Educação escolar e pesquisa na teoria histórico-cultural. São Paulo, ed. Loyola, 13-45.

Duarte, N. (2016). Relações entre conhecimento escolar e liberdade. Cadernos de Pesquisa. 46(159), 78-102. 
Research, Society and Development, v. 10, n. 12, e141101220099, 2021

(CC BY 4.0) | ISSN 2525-3409 | DOI: http://dx.doi.org/10.33448/rsd-v10i12.20099

Leontiev, A. N. (1978). O desenvolvimento do psiquismo. Lisboa: Livros Horizonte.

Lopes, A. F. \& Silva, S. A. F. da. (2020). Movimento formativo de professores dos anos iniciais sobre fração: o inteiro. Research, Society and Development. 9(10). DOI: 10.33448/rsd-v9i10.9179. Disponível em: https://rsdjournal.org/index.php/rsd/article/view/9179. Acesso em: 13 set. 2021.

Lopes, A. R. L. V. (2009). Aprendizagem da docência em matemática: o Clube de Matemática como espaço de formação inicial de professores. Passo Fundo: Ed. Universidade de Passo Fundo.

Lopes, A. R. L. V.; Moura, M. O. de; Araujo, Elaine S. \& Cedro, W. L. (2016). Trabalho coletivo e organização do ensino de matemática: princípios e práticas. Zetetiké, FE/UNICAMP \& FEUFF, 24(45).

Martins, L. M. \& Eidt, N. M. (2010). Trabalho e atividade: categorias de análise na psicologia histórico-cultural do desenvolvimento. Psicologia em estudo. Departamento de Psicologia - UEM, 15(4), 675-683.

Moretti, V. D. (2007). Professores de matemática em atividade de ensino: Uma perspectiva histórico-cultural para a formação docente. 208. Tese (Doutorado em Educação) - Programa de Pós-Graduação em Educação - Ensino de Ciências e Matemática, Faculdade de Educação da Universidade de São Paulo.

Moretti, V. D. \& Moura, M. O. de. (2010). A formação docente na perspectiva Histórico-Cultural: em busca da superação da competência individual. Psicologia política. São Paulo, 10(20), 345-361.

Moura, M. O. de. (2005). Espaços de aprendizagem e formação compartilhada. Revista de Educação - PUC. Campinas, (18), 91-97.

Moura, M. O. de. (2000). O educador matemático na coletividade de formação: uma experiência com a escola pública. São Paulo, SP. Tese de LivreDocência/FEUSP). Universidade de São Paulo.

Rosa, J. E.; Damazio, A. \& Alves, E. de S. B. (2013). Adição e subtração em Davýdov. Boletim GEPEM, (63), 61-75.

Santos, Y. P. (2019). Formação continuada de professores dos anos iniciais sobre multiplicação e divisão: aprendizagens no coletivo. Dissertação (Mestrado em Educação) - Programa de Pós-Graduação em Educação de Ciências e Matemática, Instituto Federal do Espírito Santo, Vitória.

Vigotski, L. S. (2003). Psicologia Pedagógica. Tradução de Claudia Schilling - Artmed.

Vigotski, L. S. (2010). Psicologia pedagógica: tradução do russo e introdução de Paulo Bezerra. (3. ed.) Editora WMF Martins Fontes, (Coleção textos de psicologia). 445-464.

Zuge, V. \& Lopes, A. R. L. V. (2016). Políticas públicas de formação de professores: um olhar para o PNAIC como espaço de aprendizagem da docência in: Cedro, W. L. \& Lopes, A. R. L. V. (Orgs.). O sistema de avaliação e os programas de formação de professores da educação básica. Coleção: Princípios e práticas da organização do ensino de matemática nos anos iniciais. Campinas, SP: Pontes Editores, 159-174. 